Tsaqofiya : Jurnal Pendidikan Bahasa dan Sastra Arab

Vol. 3 No. 2 Juli 2021, 189-198

P-ISSN : 2685-7022, E-ISSN : 2685-7103

DOI : https://doi.org/10.21154/tsaqofiya.v3i2.76

\title{
PENGGUNAAN MEDIA PEMBELAJARAN BAHASA ARAB BERBASIS VIDEO UNTUK MENINGKATKAN MAHARAH KALAM DALAM KITAB AL ARABIYYAH LIN NASYIIN
}

\author{
Muhammad Nashrullah', Nur Halim², Rijalul Ghifari Al Fanani ${ }^{3}$ \\ ${ }^{1}$ UIN Sunan Ampel Surabaya \\ 1 mnshrljbg@gmail.com²pustalukisankaligrafi@gmail.com \\ 3rijalulghifar_alfanani@yahoo.co.id
}

Abstract

This research is motivated by the difficulties of students in speaking skill learning which are influenced by several factors, namely students' internal factors, including low understanding and dismissive attitudes, and external factors in the form of teachers who are still not precise in choosing learning techniques or methods, as well as factors from schools, namely tools or learning media that are still not evenly distributed. Therefore, this study aims to describe how to apply the Kitab Al Arabiyyah Lin Nasyiin with a video-based learning media. This study uses a qualitative method, the data generated is not in the form of numbers. The results of this study are the use of video-based media is very interesting for students because the video is audio-visual.

Keywords: Al Arabiyyah Lin Nasyiin, Learning Media, speaking skill

\section{Asbtrak}

Penelitian ini dilatarbelakangi adanya kesulitan siswa yang berkaitan dengan kemampuan berbicara yang dipengaruhi oleh beberapa faktor, yaitu factor internal peserta didik, meliputi rendahnya pemahaman dan sikap yang meremehkan, dan faktor eksternal berupa guru yang masih kurang tepat dalam memilih tehnik atau metode pembelajaran, serta faktor dari sekolah, yaitu alat bantu atau media pembelajaran yang masih belum merata. Oleh karena itu, penelitian ini bertujuan untuk mendeskripsikan cara mengaplikasikan Kitab Al Arabiyyah Lin Nasyiin dengan sebuah media pembelajaran berbasis video. Penelitian ini menggunakan metode kualitatif, data yang dihasilkan bukan berupa angka-angka. Adapun hasil dari penelitian ini yaitu penggunaan media berbasis video sangatlah menarik bagi siswa dikarenakan dalam video tersebut bersifat audio-visual.

Kata Kunci: Al Arabiyyah Lin Nasyiin, Media Pembelajaran, Maharah Kalam

\section{PENDAHULUAN}

Pendidikan merupakan pendewasaan peserta didik agar dapat mengembangkan bakat, potensi dan keterampilan yang dimiliki dalam menjalani kehidupan, oleh karena itu sudah seharusnya pendidikan didesain guna memberikan pemahaman serta meningkatkan prestasi belajar peserta didik. Untuk mendesain 
pendidikan yang menarik bagi peserta didik itu tidaklah mudah, karena anak didik sering cepat merasa bosan dan kelelahan yang tidak dapat dihindari ketika sedang melakukan proses pembelajaran, disebabkan karena penjelasan guru yang sukar dicerna dan dipahami.

Dewasa ini kecenderungan pembelajaran yang kurang menarik merupakan hal yang wajar yang dialami oleh guru, yang mana mereka tidak memahami kebutuhan dari siswanya baik dalam karakteristik, maupun dalam pengembangan ilmu dari suatu materi yang dipelajari. Setiap materi pelajaran tentu memiliki tingkat kesukaran yang bervariasi. Pada satu sisi ada bahan pelajaran yang sangat memerlukan alat bantu berupa media pengajaran. Karena bahan yang tinggi sukar diproses oleh peserta didik, apalagi bagi peserta didik yang kurang menyukai bahan pelajaran yang disampaikan oleh guru. Maka dari itu, media sebagai alat bantu dalam proses belajar mengajar adalah suatu kenyataan yang tidak dapat dipungkiri. ${ }^{1}$

Dalam berbicara bahasa Arab terdapat kesulitan yang dihadapi peserta didik terletak pada penguasaan kosa kata yang kurang, latar belakang pendidikan sebelumnya. Mereka sering kali mengalami kesulitan yang berkaitan dengan kemampuan berbicara. ${ }^{2}$ Kesulitan yang dialami peserta didik dalam berbicara bahasa Arab dipengaruhi oleh beberapa faktor, di antaranya faktor pada diri peserta didik pemahaman peserta didik masih kurang terhadap keterampilan berbicara bahasa Arab, dan sikap peserta didik yang meremehkan kegiatan berbicara mengunakan bahasa Arab. Selain itu, faktor pada guru yaitu guru masih kurang tepat dalam memilih tehnik atau metode yang sesuai dengan proses pembelajaran keterampilan berbicara bahasa Arab. Adapun faktor dari sekolah, yaitu alat bantu atau media pembelajaran yang masih belum merata keberadaanya di sekolah-sekolah. Hal-hal tersebut menyebabkan keterampilan berbicara bahasa Arab siswa di kelas tidak sesuai dengan target yang diinginkan, yaitu pada kategori baik.

Pada penelitian terdahulu yang berjudul Implementasi Kitab Al Arabiyyah Lin Nasyiin dalam Pembelajaran Insya' di Pondok Pesantren Ar-Raudatul Ilmiyyah Kertosono Nganjuk dikatakan bahwa kitab Al Arabiyyah Lin Nasyiinjika ditinjau dari

\footnotetext{
1 Jamaluddin Shiddiq, "Inovasi Pemanfaatan Word-Wall Sebagai Media Game-Based Learning Untuk Bahasa Arab," JALIE; Journal of Applied Linguistics and Islamic Education 5, no. 1 (2021): 151-69.

2 Rosiana Anggraini Dewi and Ahmad Zubaidi, "Al-Diraasaat Al-Taqaabuliyyat Bayna AlAshwaat Al-'Arabiyyat Wa Al-Induuniisiyyaat Wa Tathbiiquhaa Fii Ta'Liim Al-Lughat Al-'Arabiyyat Li Khidmati Al-Thullab Fii Tadriis Al-Lughat Al-'Arabiyyat," Tsaqofiya: Jurnal Pendidikan Bahasa Dan Sastra Arab 1, no. 1 (2019): 55-75.
} 
proses penyusunan materi telah memenuhi kriteria seleksi, gradasi, presentasi dan repetisi. ${ }^{3}$ Meskipun kitab Al Arabiyyah Lin Nasyiin telah memenuhi kriteria sebagai buku ajar yang baik, namun hal tersebut belum membuktikan bahwa kitab tersebut efektif digunakan dalam pembelajaran bahasa Arab.

Penulis merasa tergugah dalam pengaplikasian kitab Al Arabiyyah Lin Nasyiin mengunakan media video dalam meningkatkan keterampilan berbicara khususnya berbicara bahasa Arab, yang diharapkan dapat meningkatkan keterampilan berbicara bahasa Arab.

\section{METODE}

Prosedur penelitian ini menggunakan metode kualitatif, yang mana akan menghasilkan data deskriptif berupa kata-kata tertulis dengan jenis penelitian kepustakaan atau library research yang memanfaatkan sumber kepustakaan untuk memperoleh data penelitian. ${ }^{4}$

Tentunya prosedur penelitian ini tidak dapat diekspresikan dengan statistik atau cara-cara kuantifikasi. Dalam hal ini peneliti mengumpulkan data dari media pembelajaran dengan menggunakan video, kemudian melakukan analisis dari berbagai literatur terkait.

\section{Pembahasan}

\section{Media Pembelajaran}

Kata media berasal dari bahasa latin yang merupakan bentuk jama' dari medium yang secara harfiah berarti perantara atau pengantar, yaitu perantara antara pengirim pesan dan penerima pesan. Menurut Schram, media pembelajaran adalah teknologi pembawa pesan yang dapat dimanfaatkan untuk keperluan pembelajaran. Sudrajat juga mengutip definisi dari Briggs bahwa media pembelajaran adalah, secara fisik untuk menyampaikan isi materi pembelajaran, misalnya buku, film, video, dan sebagainya. 5

Suparno mengemukakan bahwa media pembelajaran adalah segala yang digunakan sebagai saluran untuk menyampaikan pesan atau informasi dari satu

\footnotetext{
3 Dewi Mustika Rahma, "Implementasi Kitab Al Arabiyyah Lin Nasyiin Dalam Pembelajaran Insya' Di Pondok Pesantren Ar-Raudatul Ilmiyyah Kertosono Nganjuk" (UIN Sunan Kalijaga, 2006).

${ }^{4}$ J Moleong Lexy, "Metodologi Penelitian Kualitatif," Bandung: Remaja Rosdakarya, 2002, 4.

5 Imam Asrori and Moh Ahsanuddin, "Media Pembelajaran Bahasa Arab Dari Kartu Sederhana Sampai Web Penjelajah Dunia," Malang: CV. Bintang Sejahtera, 2016, 3.
} 
sumber kepada penerima pesan.Suatu pesan kadang-kadang disampaikan melalui saluran audio (dengar), misalnya melalui radio.Radio tersebut merupakan media audio.Suatu pesan juga dapat disampaikan melalui saluran visual (pandang), misalnya melalui gambar. Gambar yang digunakan untuk menyampaikan informasi tersebut merupakan media visual. Suatu pesan juga sering disampaikan melalui gabungan pandang dan dengar, misalnya televisi. Televisi yang digunakan untuk menyampaikan informasi tersebut merupakan media audio-visual. Suparno menambahkan bahwa keberadaan pembelajaran media pembelajaran selalu tergantung pada guru. Media pembelajaran tertentu dapat menyampaikan pesan dan informasi meskipun tanpa kehadiran seorang guru. Bahkan para pakar mengemukakan bahwa media pembelajaran dapat menggantikan keberadaan guru, sebagaimana yang berlangsung dalam pembelajaran terprogram dan pembelajaran jarak jauh. 6

Pertanyaan yang sering muncul adalah mempertanyakan pentinya media dalam pembelajaran. Sebelumnya, harus diketahui terlebih dahulu konsep abstrak dan konkrit dalam pembelajaran, karena proses belajar mengajar hakikatnya adalah proses komunikasi, penyampaian pesan dari pengantar ke penerima. Pesan berupa isi atau ajaran yang dituangkan ke dalam symbol-simbol komunikasi baik verbal (katakata tulisan) maupun non verbal, proses ini dinamakan enconding.Dalam penafsiran tersebut, ada kalanya berhasil dan ada kalanya tidak berhasil atau gagal. Dengan kata lain dapat dikatakan kegagalan atau ketidakberhasilan dalam memahami apa yang didengar, dibaca, dilihat, atau diamati. ${ }^{7}$

Dalam proses belajar mengajar kehadiran media mempunyai arti yang cukup penting. Karena dalam kegiatan tersebut ketidak jelasan bahan yang disampaikan dapat dibantu dengan menghadirkan media sebagai perantara. Kerumitan bahan yang akan disampaikan kepada peserta didik dapat disederhanakan dengan bantuan media. Media dapat mewakili apa yang kurang mampu guru ucapkan kata-kata atau kalimat tertentu. Bahkan keabstrakkan bahan dapat dikonkretkan dengan kehadiran media. Namun perlu diingat bahwa peranan media tidak akan terlihat bila penggunanya tidak sejalan dengan isi dari tujuan pengajaran yang telah dirumuskan.

\footnotetext{
${ }^{6}$ Asrori and Ahsanuddin, "Media Pembelajaran Bahasa Arab Dari Kartu Sederhana Sampai Web Penjelajah Dunia."

7 Pendekatan Pembelajaran Saintifik Kurikulum Daryanto, "Yogyakarta: Gava Media, 2014," 2013,4 .
} 
Karena itu tujuan pengajaran harus dijadikan sebagai pangkal acuan untuk menggunakan media. Jika diabaikan, maka media bukan sebagai alat bantu pengajaran, tetapi sebagai penghambbat dalam pencapaian tujuan secara efektif dan efisien. ${ }^{8}$

\section{Media Audio Visual}

Media audio-visual merupakan merupakan media pembelajaran yang digunakan guru untuk menyampaikan materi agar diterima siswa melalui indera pendengar dan penglihat secara terpadu.Media audio-visual mencakup siaran TV, rekaman VCD, dan pentas drama atau sandiwara. ${ }^{9}$

Pada dewasa terakhir ini, media audio-visual dikembangkan lebih lanjut dengan mengintegrasikan kata-kata, warna, suara, dan gerak. Jenis yang terakhir ini disebut dengan multimedia. Pembelajaran berbasis multimedia melibatkan indera pendengaran atau penglihatan melalui media teksa, visual diam, visual gerak, dan audio serta media interaktif berbasis komputer dan teknologi informasi dan komunikasi.

Mayer mendefinisikan multimedia sebagai media yang menghasilkan bunyi dan teks. Berdasarkan definisi ini, TV, presentasi powerpoint yang menampilkan teks dan gambar bersuara termasuk kategori multimedia. Berbeda dengan hal tersebut, martin membedakan multimedia dan audio-visual. Adapun aplikasi komputer interaktif dan nin interaktif merupakan multimedia. Jadi multimedia adalah media berbasis komputer yang mengintregasikan berbagai jenis media.

Multimedia merupakan pengembangan istilah dari audio-visual.Disebut multimedia sebab melibatkan banyak unsur sekaligus, yaitu unsur warna, suara, gerak, ukuran, dan lain-lain.Dengan demikian, media audio-visual pun pada dasrnya tidak berbeda dengan multimedia, karena media audio-visual misalnya pentas drama, juga melibatkan berbagai unsur sekaligus, baik warna, gerak, maupun suara dan lainya. ${ }^{10}$

Hal ini selaras dengan apa yang diungkapkan Ahmad Rohani dalam bukunya, bahwa media audio-visual merupakan media instruksional modern yang sesuai

\footnotetext{
(2006).

${ }^{8}$ Syaiful Bahri Djamarah and Aswan Zain, "Strategi Belajar Mengajar," Jakarta: Rineka Cipta 46

${ }_{9}$ Asrori and Ahsanuddin, "Media Pembelajaran Bahasa Arab Dari Kartu Sederhana Sampai Web Penjelajah Dunia."

${ }_{10}$ Mohammad Ahsanuddin, "Analisis Hasil TOAFL Mahasiswa Jurusan Sastra Arab Fakultas Sastra Universitas Negeri Malang," in Prosiding Konfererensi Nasional Bahasa Arab, vol. 1, 2016.
} 
dengan perkembangan zaman (kemajuan ilmu pengetahuan dan teknologi) yang meliputi media yang dapat dilihat, didengar dan dilihat, sebagaimana berikut ini: ${ }^{11}$

\section{Film atau Video}

Film atau video adalah salah satu jenis media audio-visual. Dibandingkan dengan media yang lain film atau video mempunyai kelebihan sebagai berikut :

1) Penerima pesan akan mudah memperoleh tanggapan yang lebih jelas dan tidak mudah melupakan, karena antara melihat dan mendengar dapat dikombinasikan menjadi satu.

2) Dapat menikati kejadian dalam waktu yang lama pada suatu proses atau peritiwa tertentu.

3) Dengan tehnik slow-motion dapat mengikuti suatu gerakan atau aktivitas yang berlangsung cepat.

4) Dapat mengatasi keterbatasan ruang dan waktu.

5) Dapat membangun sikap, perbuatan, dan membangkitkan emosi dan mengembangkan problema.

\section{Pengertian Berbicara}

Berbicara adalah suatu kemampuan mengucapkan bunyi-bunyi artikulasi atau kata-kata untuk mengekspresikan, menyatakan serta menyampaikan pikiran, gagasan dan perasaan. ${ }^{12}$ Dapat dikatan bahwa berbicara merupakan suatu sistem tanda-tanda yang dapat dedengar dan yang kelihatan yang memanfaatkan sejumlah otot tubuh manusia demi maksud dan tujuan gagasan atau ide-ide yang dikombinasikan. Berbicara merupakan suatu bentuk perilaku manusia yang memanfaatkan faktorfaktor fisik, psikologis, neurologis, semantik, dan linguistik.

Menurut Nurgiyantoro berbicara adalah aktivitas berbahasa kedua yang dilakukan manusia dalam kehidupan berbahasa, yaitu setelah mendengar. Berdasarkan bunyi-bunyi yang didengar itu, kemudian manusia belajar untuk mengucapkan dan akhirnya terampil berbicara. ${ }^{13}$

Manusia memiliki kecenderungan untuk berfikir dan menyatakan pendapat, keinginan, perasaan serta pengalaman-pengalamannya. Disamping itu, manusia kecenderungan mempengaruhi bahkan memaksakan pikiran dan pendapatnya

\footnotetext{
11 Rohani Ahmad, Media Instruksional Edukatif(Pt Rineka Cipta, 1997), 97.

12 Henry Guntur Tarigan, "Menulis Sebagai Suatu Ketrampilan Berbahasa," 1994, 15.

13 Nurgiyantoro Burhan, "Penilaian Pembelajaran Bahasa Berbasis Kompetensi," Yogyakarta: BPFE-Yogyakarta, 2014, 399.
} 
kepada orang lain atau kelompok. Umumnya, kecenderungan tersebut dilakukan secara langsung melalui pembicaraan (proses komunikasi), baik antar pribadi maupun dalam kelompok. ${ }^{14}$

Handoro Sameto menyatakan bahwa berbicara merupakan saran penyampaian ide kepada orang atau khalayak secara lisan dengan cara yang mudah dicerna dan dimengerti oleh pendengarnya. ${ }^{15}$

\section{Buku Ajar Al Arabiyyah Lin Nasyiin}

Yang dimaksud dengan buku ajar yaitu buku yang dijadikan pedoman siswa pada jenjang tertentu sebagai media pembelajaran, yang berkaitan dengan mata pelajaran tertentu. Buku ajar adalah buku yang diterbitkan oleh para pakar dalam bidangnya, yang dilengkapi dengan sarana pembelajaran dan digunakan sebagai pendukung program pembelajaran. ${ }^{16}$

Direktorat pendidikan menengah umum menyebutkan buku ajar adalah sekumpulan tulisan yang dibuat secara terorganisir, berisi materi pelajaran tertentu yang disiapkan oleh pengarangnya, kurikulum yang berlaku sebagai acuannya. Substansi yang ada dalam buku diturunkan dalam kompetensi yang wajib difahami oleh pembacanya. ${ }^{17}$

Dari definisi di atas dapat disimpulkan buku ajar merupakan bagian bahan ajar yang didalamnya terdapat materi yang mendukung untuk sampai pada tujuan pembelajaran yang dirancang oleh para ahli secara sistematis.

Kitab Al Arabiyyah Lin Nasyiin adalah sebuah kitab yang digunakan kegiatan belajar mengajar pada mata pelajaran bahasa Arab yang terdiri dari enam jilid yang mencankup muhadatsah, qiro'ah, dan kitabah yang dikarang oleh Dr. Mahmud Ismail Sini, Nasif Musthofa, Abdul Aziz Thohir Husein. Salah satu tujuan sebagai solusi untuk mengatasi berbagai permasalahan pembelajaran khususnya dalam pemerolehan keterampilan dalam bahasa Arab.

Buku ini terdiri dari enam jilid dan tujuannya adalah mengasah keterampilan peserta didik untuk dapat membaca dan menulis bahasa Arab. Buku ajar Al Arabiyyah

${ }^{14}$ Gentasari Anwar, Retorika Praktis Teknik Dan Seni Berpidato (Jakarta: Rineka Cipta, 1995).

15 Handoro Sameto, Cara Berbicara Presentasi Audio-Visual (Jakarta: PT Gramedia Pustaka Utama, 2002).

16 Pusat Perbukuan, Pemilihan Dan Pemanfaatan Buku Teks Pelajaran Yang Memenuhi Syarat Kelayakan (Jakarta: Pusat Perbukuan Departemen Pendidikan Nasional, 2006).

17 Direktorat pendidikan menengah Umum, Pedoman Memilih Buku SMA (Jakarta: Direktorat Pendidikan Menengah Umum, Direktorat Jendral menejemen pendidikan dasar dan menengah, departemen pendidikan nasional, 2004). 
Lin Nasyiin ini diperuntuhkan bagi peserta didik yang sudah matang, baik di pendidikan formal, non formal maupun belajar mandiri. Selain itu dapat juga digunakan pada program pembelajaran intensif atau pun non intensif. Pada sisi yang lain, buku ajar ini juga digunakan oleh peserta didik yang belum pernah sama sekali belajar bahasa Arab, dimulai dari nol, sehingga mereka bisa berkomunikasi dengan penutur asli baik lisan maupun tulisan dan mereka juga bisa memasuki perguruan tinggi yang mengunakan bahasa Arab sebagai bahasa pengantar.

Berdasarkan analisis data dalam video yang berdurasi 09.21 menit diperoleh hasil sebagai berikut:

Pada video bagian I menit ke 00.00-03.52, terdapat kalimat yang diucapkan oleh pembicara yaitu, دخل مدير الصف ومعه مدرس جديد dalam video tersebut menjelaskan kata-kata sulit, berupa kata دخل X خرج dan kata الصف yang memiliki makna الفصل yaitu kelas. Setelah menjelaskan tentang kata sulit dalam video tersebut guru memerintahkan para siswa untuk menjawab pertanyaan.

Tujuan diberikannya kata-kata sulit tersebut agar para siswa dapat memahami kaliamat yang telah diberiakan dan kemudian dapat menjawab pertanyaan tentang materi pembelajaraan pada video bagian I ini.

Pada video bagian II menit ke 03.52-07.00 terdapat kalimat yang diucapkan oleh pembicara yaitu:

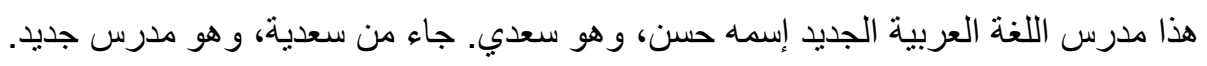

Pada video kedua ini menceritakan tentang guru pengajar bahasa Arab yang baru, guru tersebut bernama Hasan berasal dari Arab Saudi. Setelah itu kemudian para siswa diperintahkan untuk menjawab pertanyaan yang berkaitan tentang cerita yang telah diperdengarkan sebelumnya.

Untuk mengatahui tingkat pemahaman dan kelancaran berbicara siswa dalam keterampilan berbicara / Maharah Kalam dengan menjawab pertanyaan guru yang disampaikan dalam video.

Pada video bagian III menit ke 07.00-09.21, terdapat kalimat yang diucapkan oleh pembicara yaitu:

$$
\text { خرج المدير من الصف وجلس التلاميذ على الكراسي. }
$$

Dalam video tersebut menjelaskan bahwa kepala sekolah telah keluar dari ruang kelas dan murid-murid duduk dikursi-kursi mereka. Dalam video tersebut juga menjelaskan kata الكر اسيmerupakan bentuk jamak dari كرسي. 
Setelah itu guru memerintahkan kepada peseta didik agar mendengarkan lalu kemudian dipraktekkan dalam bicara, dan menjawab pertanyaan yang telah diberikan.

Untuk mengetahui tingkat pemahaman dan kelancaran berbicara peserta didik dalam maharah kalamya itu dengan kefasihan berbicaranya dan pemahaman isi teks tersebut.

Hasil dalam penelitian ini mengindikasikan bahwa penggunaan media pembelajaran bahasa Arab berbasis video akan lebih mudah dalam pemahaman dikarenakan video yang dibuat membantu dalam pembelajaran bahasa Arab dan mempunyai daya tarikkeingin tahuan bagi peserta didik.

\section{SIMPULAN}

Sebuah pembelajaran bahasa Arab dengan menggunakan kitab Al-Arrobiyyah Lin Nasyiin dalam keterampilan berbicara atau Maharah Kalam dengan media video dapat menjadi alternatif pembelajaran bahasa Arab selain pembelajaran bahasa Arab dengan tatap muka, dapat juga menghindari kesalahan dalam penyampaian materinya. Tetapi juga terdapat permasalahan dalam pembelajaran bahasa Arab Maharah Kalam yaitu kurangnya sebuah media pembelajaran berbasis video untuk meningkatkan kemampuan Maharah Kalam bagi pelajar bahasa Arab. Maka dengan adanya penelitian ini diharapkan dapat menjawab permasalahan tersebut.

\section{DAFTAR PUSTAKA}

Ahmad, Rohani. Media Instruksional Edukatif. Pt Rineka Cipta, 1997.

Ahsanuddin, Mohammad. "Analisis Hasil TOAFL Mahasiswa Jurusan Sastra Arab Fakultas Sastra Universitas Negeri Malang.” In Prosiding Konfererensi Nasional Bahasa Arab, Vol. 1, 2016.

Anwar, Gentasari. Retorika Praktis Teknik Dan Seni Berpidato. Jakarta: Rineka Cipta, 1995.

Asrori, Imam, and Moh Ahsanuddin. "Media Pembelajaran Bahasa Arab Dari Kartu Sederhana Sampai Web Penjelajah Dunia." Malang: CV. Bintang Sejahtera, 2016. Burhan, Nurgiyantoro. "Penilaian Pembelajaran Bahasa Berbasis Kompetensi." Yogyakarta: BPFE-Yogyakarta, 2014.

Daryanto, Pendekatan Pembelajaran Saintifik Kurikulum. "Yogyakarta: Gava Media, 
2014," 2013.

Dewi, Rosiana Anggraini, and Ahmad Zubaidi. “Al-Diraasaat Al-Taqaabuliyyat Bayna Al-Ashwaat Al-'Arabiyyat Wa Al-Induuniisiyyaat Wa Tathbiiquhaa Fii Ta'Liim AlLughat Al-'Arabiyyat Li Khidmati Al-Thullab Fii Tadriis Al-Lughat Al-'Arabiyyat." Tsaqofiya: Jurnal Pendidikan Bahasa Dan Sastra Arab 1, no. 1 (2019): 55-75.

Djamarah, Syaiful Bahri, and Aswan Zain. "Strategi Belajar Mengajar.” Jakarta: Rineka Cipta 46 (2006).

Lexy, J Moleong. "Metodologi Penelitian Kualitatif." Bandung: Remaja Rosdakarya, 2002.

Perbukuan, Pusat. Pemilihan Dan Pemanfaatan Buku Teks Pelajaran Yang Memenuhi Syarat Kelayakan. Jakarta: Pusat Perbukuan Departemen Pendidikan Nasional, 2006.

Rahma, Dewi Mustika. "Implementasi Kitab Al Arabiyyah Lin Nasyiin Dalam Pembelajaran Insya' Di Pondok Pesantren Ar-Raudatul Ilmiyyah Kertosono Nganjuk." UIN Sunan Kalijaga, 2006.

Sameto, Handoro. Cara Berbicara Presentasi Audio-Visual. Jakarta: PT Gramedia Pustaka Utama, 2002.

Shiddiq, Jamaluddin. "Inovasi Pemanfaatan Word-Wall Sebagai Media Game-Based Learning Untuk Bahasa Arab." JALIE; Journal of Applied Linguistics and Islamic Education 5, no. 1 (2021): 151-69.

Tarigan, Henry Guntur. “Menulis Sebagai Suatu Ketrampilan Berbahasa,” 1994.

Umum, Direktorat pendidikan menengah. Pedoman Memilih Buku SMA. Jakarta: Direktorat Pendidikan Menengah Umum, Direktorat Jendral menejemen pendidikan dasar dan menengah, departemen pendidikan nasional, 2004. 